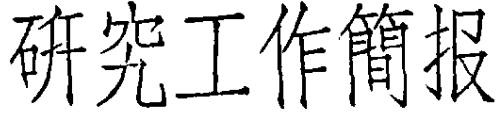

\section{分析粉末試样中微墨卤素用的 一种新的双电弧光譜光源}

不久以前我門算提怕过一种光諧分析用的新的双 电弧电路[1]（見圖 1)。实驗証:明这纯路和过去一般 的双电弧电路比較, 光管再現性較好, 抹且还有一个 特点, 邰激發放电的性能可以独立地在很大的沾圍內 (弧光性至电花性) 随意改变。但是这电路 还有一个 跳点, 即激發放电迴路中的感 $L_{1}$ 不能太小，否則不 能工作。例如在我們的工作条件下，当 $L_{1}<30 \mu H$ 时, 即使放电隙 $G_{1}$ 小至 $1 \mathrm{~mm}$, 激發放电也不能被引

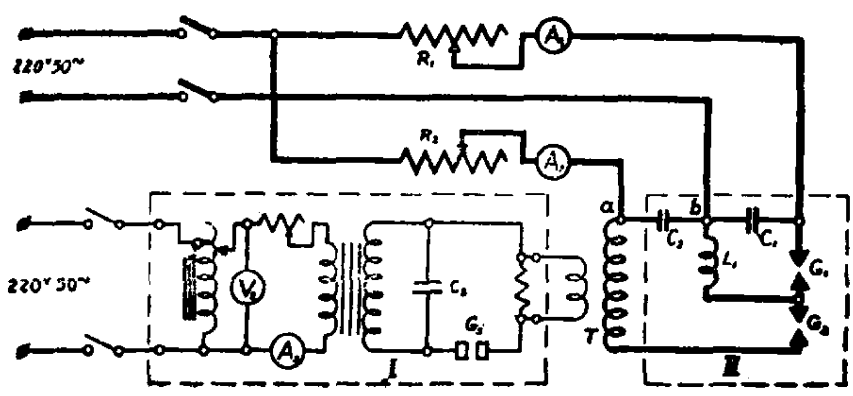

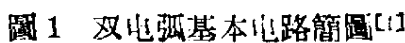

$I$-一引燃装置 (ИГ-2, 每秒引燃 100 次),$I I-$ АбрамСон 附加地路, T- Tesla 变压器, $C_{1}-L_{1}-G_{1}-$

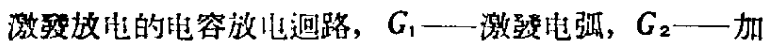
热电弧， $G_{2}$-一隔值心容。粗綫表示双电弧强流部分

㚙。这是因为加热电弧有:一般工作情况下是自持的, 在自持加热电弧形成之后, 所有的高頻引燃脉冲都将 总是在放电隙 $G_{2}$ 已称为加热电抔所短路时通过 $G_{2}$; 这样如果 $L_{1}$ 小于某一限值, 在它的两端就不能得到 足以击第 $G_{1}$ 的高頻电压，以致激發放电不能被引燃。

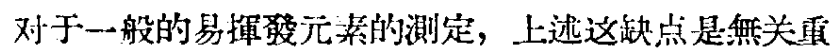
要的; 但是如果要测徒某些“难激發”的易揮發元素如 㐫素等，它就会成为提高灵敏度的严重障碍。

为了要克服这缺点，我們最近改进了这个电路。 改进电路見圖 2。圖中 $G_{1}$ 及 $G_{2}$ 分别为激發及加热放 电柗, $G_{3}$ 則是新添的輔助放电隙。电路的工作原理和 以前的相仿, 即来自 Tesla 变压器的䕐頻电压先把 $G_{2}$ 及 $G_{3}$ 击第，从而把加热电弧引燃，然后差不多全 部电压移至 $L_{1}$ 上，击穿 $G_{1}$ 而把激敃放电引燃。所 不同的只是 $C_{1}$ 的光电迥路任拈了 $L_{2}, L_{1}$ 及 $L_{3}$, 而加 热电流不經过 Tesla 变压器, 也不經过 $G_{3}$ 。因为加 热电流不經过 $G_{3}$ ，所以在每次高頻引燃放电衰灭后， $G_{3}$ 总是断路的, 不管 $G_{2}$ 是否被加热电弧所短路。这

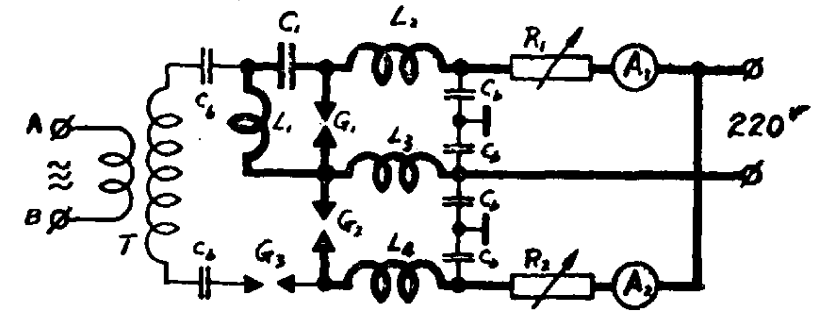

围 2 改进电路

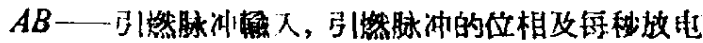

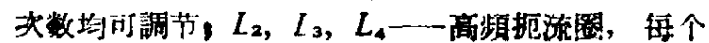
$\geqslant 350 \mu H ; r_{B} \cdots$ 隔㨁电谷; $G_{3}$ 一一輔助 电花媍。 其余标志与踏 1 网。

sla 变压器的二次高頻电压已經达到足够的幅 传, 使 得当 $L_{1}$ 小至約 $3 \mu H$ 时, 即使 $G_{1}$ 倜大至 $2 \mathrm{~mm}$, 激發 放电仍能被引燃（其他条件和以前一样）。

我門曾安装了一个电路与圖 2 穕有不同的交流加: 热、直流光电的实驗洗源（胃 3)。在这个光源中引燃 电路和整流电路的电源位相相差 $120^{\circ}$ (如用三相电 源, 这一点是很易做到的)。这就可以利用普通的每秒放电 100 次的 Feussner 电花發生器获得每秒 50 次的激破放电（当然，如用放电次数及位相都可自由 調整的引然装置, 則更方便)。我們曾用这光源在 $K$ $\mathrm{C}-55$ 玻琌摄䍀仪上进行分析 $\mathrm{CuO}$ 中微量 $\mathrm{Cl}$ 及 $\mathrm{Br}$. （两者均以鉡盐状态加入）的初步实驗。实驗結 果 荆: 明，在我們的工作条件下， $\mathrm{Cl}$ 及 $\mathrm{Br}$ 的检查灵做度都 可达 $0.03 \%$ 。实驗中所用的分析是 CI II 4810.06 , Cl II 4819.46 及 Br II 4785.50 ; 电極系統和以前 的[1]相似。Лєвинтов ${ }^{[3]}$ 在用他的“热电弧”光源測是:

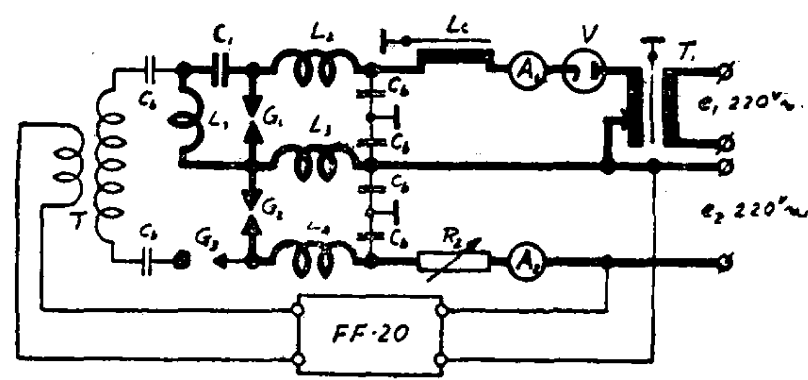

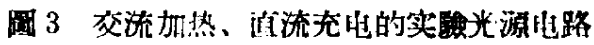

$T_{1}$ 一世游变压器, $220 / 200-400 \mathrm{~V}, 100 \mathrm{VA} 3 L_{c}$

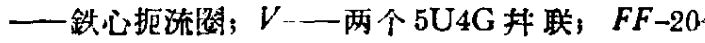
- - Feussner 电化敢生器, $V=12000 \mathrm{~V}, \mathrm{C}=500 \mathrm{pF}$; $e_{1}$ 超前于 $e_{2} 120^{\circ}$ 。

实羷条件: $C_{1}-3 \times 8 \mu F ; L_{1}-$ 䄪 $3 \mu H$ （估計

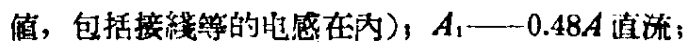
$A_{2}-16 A$ 交流; $C_{1}$ 放廹电压- $-350 \mathrm{~V}$ (示没器测 量); $G_{1}-2 \mathrm{~mm} ; G_{2}-$ 約 $2 \mathrm{~mm} ; G_{3}$-以 $\phi 5 \mathrm{~mm}$

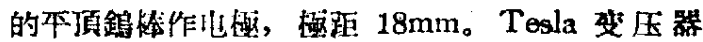
一初次 10 园，二次 150 圈，絬构及大小上 Bardócz ${ }^{[2]}$ 的相似， 只是二次经綫的綫粗得多（属 用于國 1 的电路)。 
RuO 試佯中的备素时, 对这两元素所达到的灵敉度 是 $0.15 \%$ 。他每次曝光所用的試样量約为 0.5 克。而 在我們的实驗中只用 0.3 克。可以預料, 在实驗中如 能像 Левинтов 一样使用光圈和色散率都此較大的 三个俊鏡的摄譜仪，增大試样用量，扞选用更佳的激 唚及蒸条件, 則灵敏度当可更提高。

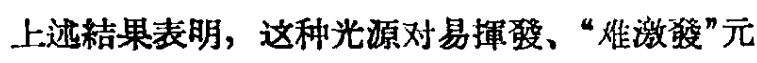
素的光譜分析是有一定的优点的。由于它能把試样的 蒸没激过程完全分开，所以还可以利用它来研究 一下到底是大电容还是小电容的低压电花对“难激墢” 元素的激郋更有利 (Pfeilsticker [4] 用几百 $\mu$ F 以上 菂电容在低气压下来激骠这类元素的光譜)。我們正 在准备对它作进一步的研究, 讲准备用它来作 $\mathrm{Cl}$ 、 $\mathrm{Br} 、 \mathrm{Se}$ 等元素的測定。

\section{黄本立田笠 楖}

(中国科学院应用化学研究所) (南京大学化学采)

\section{7 年 11 月 15 日}

[1 1] 黄本立, 科学通报, 1957 年第 10 期, 第298頁。

[2 2$]$ Bardócz, Á., Acta Physica Acad. Sci. Hungaricaen 1(3), 247(1952).

[2] Лөвинтов, И. И, Журн. тех. физ., 17 (7), 795 (1947).

[5] Pieilsticker, K., (a) Spectrochim. Acta, 1, 424 (1940), (b) Mikrochim. Acta, 1955, Heft 2-3, 358.

\section{乙酸乙酯对硝酸鈰 $(\mathbf{I V})$ 的溶剂萃取}

早在 1927 年, Imre [1]已报导了利用乙醚在硝酸 溶液中萃取銅 (IV) 的試驗, 得到了良好䊅果。此后 又有許多学者如 Bock [2]、Gryder [3]、Wylie ${ }^{[4]}$ 及

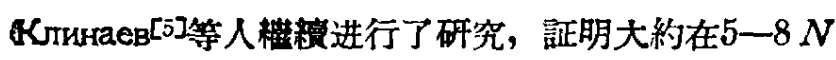

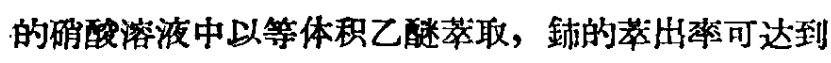
90-95\%左右。此外, Warf[6] 采用磷酸三丁酯萃取 硝酸鈰鈘，也有利用硝基里烷 ${ }^{[7]}$ 及各种醇类作錰的萃 取者，这些方法各有其优触点。

作者进行了醚、酷、䣱、醇等十余种有机溶剂对 硝酸鈰敛的萃取, 除驗証了 Imre 的結果外, 愣了 乙酸乙酯在硝酸介質中对鋪等体积单次萃出率能高达 $90 \%$ 以上，在有机相比水相体积为 50 毫仆比 25 毫升 时萃出为为 $93.89 \%$ 。因而进一步进行了乙酸乙酷萃

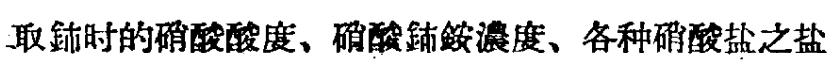
析效应对分配影响的研究。最后还进行了巨經光䜊全 定量的希土混合物中鈰的萃取，菻出本为 $92.21 \%$, 以 50 毫升溶剂比 25 毫升試料体积莁取时萃出本可
达 $94.86 \%$ ，两者純度皆为 $96 \%$ 左右，經光譛定性磷 定其他希土杂質为 La 及 $\mathrm{Y}$ 元来。实驗中还测走了各

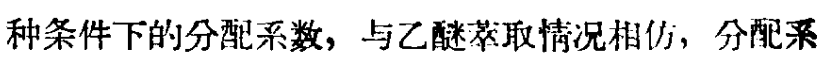
数扭不是一常数值。現将主要谈驗絬果列于下表。

表 1 酸度对鋪猝取之影响

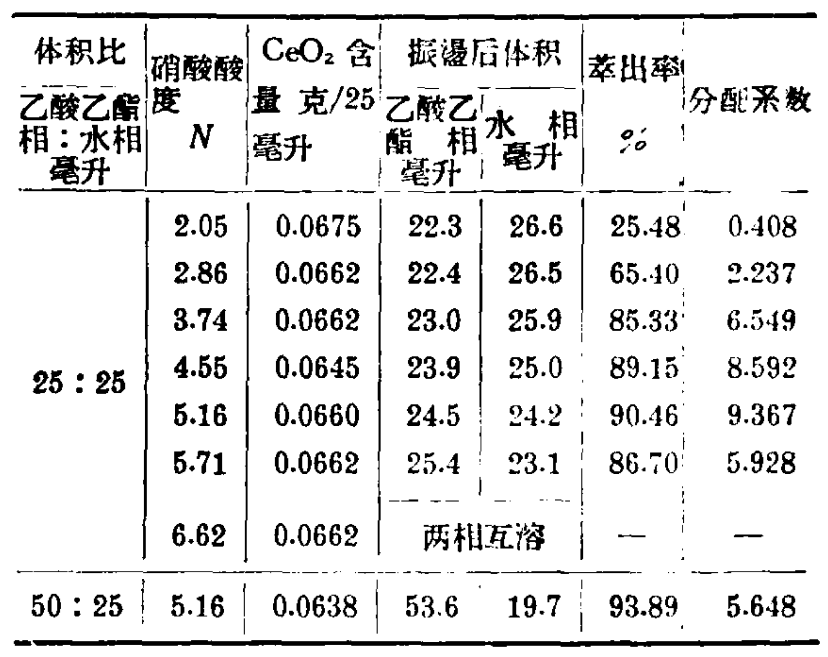

表 2 碓酸触銨農度对葆取之影响

\begin{tabular}{|c|c|c|c|c|c|}
\hline \multirow{2}{*}{$\begin{array}{l}\mathrm{CeO}_{2} \text { 含 } \\
\text { 最克/25 } \\
\text { 要升 }\end{array}$} & \multirow{2}{*}{$\begin{array}{c}\text { 䂤酸酸隹 } \\
N\end{array}$} & \multicolumn{2}{|c|}{ 振鼬后体积 } & \multirow{2}{*}{$\begin{array}{c}\text { 荻出率 } \\
\text { 品 } \\
\end{array}$} & \multirow{2}{*}{ 分配柔数 } \\
\hline & & 乙酸乙醋 & $\begin{array}{c}\text { 水 相 } \\
\text { 琵歼 }\end{array}$ & & \\
\hline 0.0320 & 5.11 & 25.2 & 23.9 & 76.26 & 3.047 \\
\hline 0.0660 & 5.16 & 24.5 & 24.2 & 90.46 & 9.367 \\
\hline 0.1380 & 5.10 & 24.6 & 24.0 & 89.91 & 8.698 \\
\hline 0.3375 & 5.21 & 25.3 & 23.3 & 90.33 & 8.604 \\
\hline 0.6459 & 5.38 & 27.0 & 21.4 & $89.32 ;$ & 6.628 \\
\hline
\end{tabular}

表 3 盐析效照

\begin{tabular}{|c|c|c|c|}
\hline 盐析 剂 & 萑出率:。 & 盐析剂 & 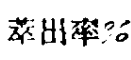 \\
\hline - & 25.48 & $\mathrm{Ca}\left(\mathrm{NO}_{3}\right)_{2}$ & 92.39 \\
\hline $\mathrm{NH}_{4} \mathrm{NO}_{3}$ & 67.10 & $\operatorname{Mg}\left(\mathrm{NO}_{3}\right)_{2}$ & 92.53 \\
\hline $\mathrm{LiNO}_{3}$ & 84.16 & $\mathrm{Zn}\left(\mathrm{NO}_{3}\right)_{2}$ & 80.54 \\
\hline $\mathrm{NaNO}_{s}$ & 90.20 & $\mathrm{Al}\left(\mathrm{NO}_{3}\right)_{3}$ & 84.20 \\
\hline
\end{tabular}

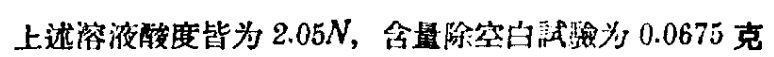
$\mathrm{CeO}_{2}$ 外, 其余皆为 0.0684 克 $\mathrm{CeO}_{2}$ 。姿碓酸酸度为 $5.16 \mathrm{~N}$

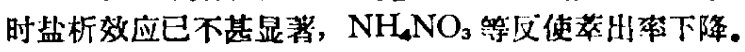

表 4 希土混合物之菻取

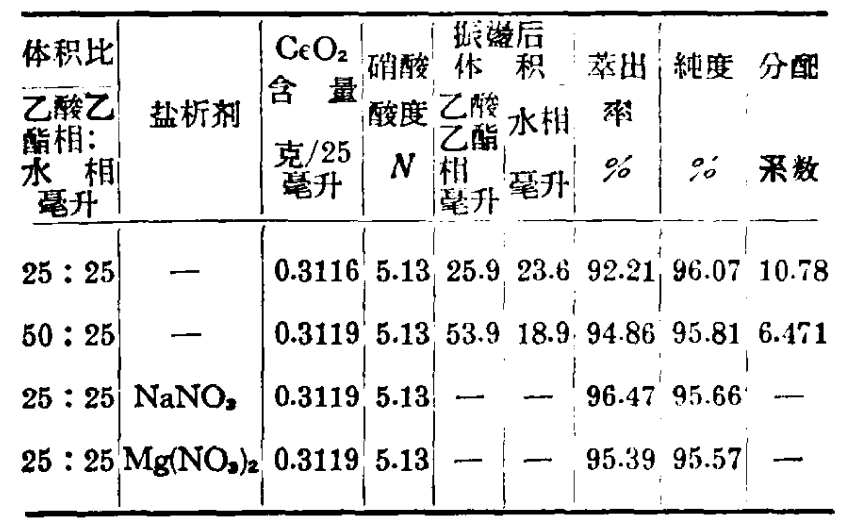

上述試料中 $\mathrm{CeO}_{2}$ : 其他常土約为 $1: 1$ 左右。 